\title{
Development of a novel nutrition screening tool for use in elderly South Africans
}

\author{
KE Charlton ${ }^{1,2, *}$, TL Kolbe-Alexander ${ }^{3}$ and JH Nel ${ }^{4}$ \\ ${ }^{1}$ Chronic Diseases of Lifestyle Unit, South African Medical Research Council, PO Box 19070, Tygerberg 7505, South \\ Africa: ${ }^{2}$ Nutrition \& Dietetics Division, School of Health and Rehabilitation Sciences, University of Cape Town, South \\ Africa: ${ }^{3}$ UCT/MRC Research Unit for Exercise Science and Sports Medicine, University of Cape Town, South Africa: \\ ${ }^{4}$ Department of Logistics, University of Stellenbosch, South Africa
}

\section{Submitted 25 April 2005: Accepted 29 June 2005}

\begin{abstract}
Objective: To develop a nutrition screening tool for use in older South Africans. Design: A cross-sectional validation study in 283 free-living and institutionalised black South Africans (60+ years).

Methods: Trained fieldworkers administered a 24-hour recall and the Mini Nutritional Assessment (MNA) screening tool, and performed anthropometric measurements and physical function tests. Cognitive function was assessed using a validated version of the Six-Item Cognitive Impairment Test. Biochemical indicators assessed included serum albumin, haemoglobin, ferritin, vitamin $\mathrm{B}_{12}$, red-blood-cell folate, cholesterol and vitamin $\mathrm{C}$. The MNA was used as the gold standard against which a novel screening tool was developed using a six-step systematic approach, namely: correspondence analysis; identification of key questions; determination of internal consistency; correlational analyses with objective measures; determination of reference cut-off values for categories of nutritional risk; and determination of sensitivity and specificity.

Results: The new screening tool includes nine separate concepts, comprising a total of 14 questions, as well as measurement of mid-upper arm circumference. The new tool score was positively associated with level of independence in either basic activities of daily living $(r=0.472)$ or the more complex instrumental activities of daily living $(r=0.233)$. A three-category scoring system of nutritional risk was developed and shown to significantly characterise subjects according to physical function tests, level of independence and cognitive function. The new tool has good sensitivity (87.5\%) and specificity (95.0\%) compared with the MNA scoring system. It has a very high negative predictive value (99.5\%), which means that the tool is unlikely to falsely classify subjects as well nourished/at risk when they are in fact malnourished.

Conclusion: A novel screening tool has been shown to have content-, construct- and criterion-related validity, and the individual items have been shown to have good internal consistency. Further validation of the tool in a new population of elderly Africans is warranted.
\end{abstract}

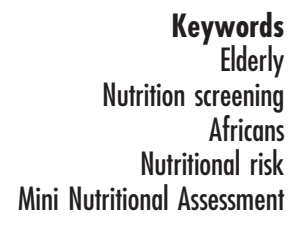

eywords

eening

Africans

Mini Nutritional Assessment
In South Africa, $6 \%$ of the black, majority population is aged 60 years and older, numbering 1.9 million people and $67.2 \%$ of the country's total population aged $60+$. A non-contributory, means-tested, state old-age pension is in existence in the country; however, nutrition programmes aimed at this vulnerable, high-risk group are virtually non-existent.

The current move towards primary health care in South Africa and other African countries indicates a need for an effective but simple nutrition screening tool that can be used by all levels of healthcare workers, particularly at community clinics. The Mini Nutritional Assessment (MNA) screening tool ${ }^{1}$ has been shown to be appropriate for use in identifying elderly black Africans who are either malnourished or who are at risk of malnutrition ${ }^{2}$. The MNA was designed to take less than 20 minutes to administer, which is reasonable for a diagnostic test, especially in a research or academic setting. However, in the public health sector in South Africa there are no dedicated geriatric health services; older adults are required to wait their turn at community clinics, whether attending for acute health problems, for the collection of chronic medications or for other reasons. Primary care community clinics in the country are severely understaffed in terms of carer-patient ratio and, within the context of these busy and often 
unorganised clinics, even 10 minutes added to a consultation would be considered too long. Further, the complexity of the MNA prohibits its widespread use by healthcare professionals in the country, as specialised training and equipment are required, particularly for anthropometric measurements. A shortened version of the MNA (MNA-Short Form or MNA-SF) was developed ${ }^{3}$ that has only six questions compared with the original 18 and which eliminates most of the time-consuming items and questions asking for subjective judgement. We have shown that, in a sample of 220 elderly South Africans, the MNA-SF is able to identify all individuals classified as malnourished on the full MNA; however, $46 \%$ of subjects classified as being at nutritional risk ( $n=52 / 114$ ) would have been missed using the MNA$\mathrm{SF}^{2}$.

Elderly populations of different countries are heterogeneous in terms of anthropometric and nutritional characteristics, which limits the generalisability of screening tools that have been validated in other countries. The use of a standardised and comprehensive instrument developed and tested in South Africa will facilitate prioritisation of individuals for entry to subsidised nutrition services such as the protein-energy malnutrition scheme and access to luncheon clubs and meals-onwheels facilities. A valid screening tool may also be used to monitor change in nutritional risk over time and evaluate the effectiveness of public health intervention strategies. In addition, comparison of the nutritional status of elderly populations in African countries requires inclusion of appropriate indicators of nutritional status that can be collected in a routine and relatively easy way. Thus the aim of the present study was to develop a nutrition screening tool for use in older South Africans.

\section{Methods}

\section{Subjects and sampling}

A cross-sectional validation study was conducted in the peri-urban areas of Cape Town, South Africa in black men and women aged 60 years and older who were either freeliving in the community or frail/institutionalised. Community-dwelling subjects were recruited from church groups, luncheon clubs and community health centre facilities, while frail subjects were recruited from state-subsidised homes for the aged, day-care centres for the elderly or from lists of applicants applying for entry into category 3 homes.* A sample size of 300 subjects was calculated using the Epi-Info statistical package (Centers for Disease Control and Prevention, Atlanta, GA, USA), assuming a prevalence of malnutrition of $30 \%$ and $15 \%$ in the frail elderly and the community-dwelling groups, respectively ( $80 \%$ statistical power and $\alpha$ error of $5 \%$ ), with an expected

*Residents requiring maximum care. attrition rate of at least 15\%. Approval for the study was granted by the Research and Ethics Committee of the University of Cape Town.

\section{Data collection}

All study subjects were interviewed by trained fieldworkers and questionnaires were administered in the subjects' home language (Xhosa), or English if preferred, in their homes. The methods have been described in detail elsewhere $^{2}$. Briefly, a 24-hour recall dietary assessment method was used to assess nutrient intake. Food security was assessed using a modified version of the 15-item Hunger and Food Security Assessment scale developed by Faul et $a l^{4}{ }^{4}$. Both the short-form screening version of the MNA (MNA-SF) and the full MNA (MNA) were completed. A score of $<11$ on the MNA-SF indicates possible malnutrition $^{3}$, while the full MNA instrument is categorised as follows: malnourished, $<17$; at risk of malnutrition, 17-23.9; well nourished, $\geq 24^{1}$. The DETERMINE nutrition screening checklist ${ }^{5}$ was also administered, for the purpose of testing whether any of the items included in this tool may be appropriate to include in the new screening tool.

The following fasting biochemical and haematological nutritional parameters were analysed according to standard protocol in the Chemical Pathology and Haematology laboratories at Groote Schuur Hospital, Cape Town: serum albumin; full blood count; red-bloodcell folate; serum vitamin $\mathrm{B}_{12}$; serum ferritin; and plasma vitamin C.

Self-reported health status was assessed using a fivescale item, and self-perceived health status, compared with peers of the same age, was assessed ${ }^{6}$. The use of, or need for, the following health aids which may impact on nutritional status, through the ability to shop for food and prepare meals or on overall quality of life, was determined: dentures, spectacles, cane/crutch/walking frame, wheelchair and hearing aid.

As a measure of functional dependence, the ability to perform activities of daily living (ADL) was assessed using both the six-item Katz ${ }^{7}$ ADL questionnaire and the 10-item Barthel $^{8}$ ADL questionnaire. Higher scores on each of these instruments indicate greater independence. A scale to assess instrumental activities of daily living (IADL) ${ }^{9}$ was administered to determine ability to perform the more sophisticated tasks of everyday life. Scoring ranges from 0 (totally dependent) to a maximum of 16 (totally independent).

Anthropometric measurements included standing height, weight, body mass index (BMI) (calculated), calf circumference, mid-thigh circumference, and triceps and biceps skinfold thicknesses. Subjects were asked to complete a battery of physical function tests, the outcomes of which were recorded by a single, trained biokineticist. The tests included the following: handgrip strength; static and dynamic balance; functional reach; chair rise, get-up- 
and-go test; and an $8 \mathrm{ft}(2.4 \mathrm{~m})$ walk. An index of motor disability was calculated as the sum of self-reported difficulties in performing six different tasks, which included (1) walking across a small room, (2) walking $400 \mathrm{~m}$, (3) walking up 10 steps, (4) doing heavy household work, (5) using fingers to grasp or handle and (6) lifting $4.5 \mathrm{~kg}$ (possible score $=0-6)^{10}$.

Cognitive function was assessed using a modified, locally validated ${ }^{11}$ version of the Six-Item Cognitive Impairment Test (6CIT), which was originally developed as a screening tool in the $\mathrm{UK}^{12}$. Scoring on the test is weighted and inverse, and measures the number of errors made by the subject for each question, with a maximum score of 28, which indicates severe dementia. The following scoring categories were used: $<10$, normal cognitive function; 10-19, impaired cognitive function; and $\geq 20$, severe cognitive impairment ${ }^{13}$.

\section{Statistical analyses and development/validation of new nutrition screening tool}

A new nutrition screening tool was developed, using the MNA instrument as the 'gold standard' against which a new set of questions was tested. A six-step systematic approach was undertaken to determine the most appropriate items to classify nutritional status in this population (see Results section).

\section{Results}

The realised sample included 232 women (81.4\% of total sample) and 53 men (18.6\% of sample), of mean age 71.5 (standard deviation (SD) 8.0) years. Twenty-seven per cent of men and $12 \%$ of women $(15 \%$ of the total sample) were institutionalised, while the remainder ( $n=242 ; 85 \%$ ) were community-dwelling. The sociodemographic characteristics of the sample are described elsewhere ${ }^{2}$.

\section{MNA classification of nutritional status}

Incomplete responses to items included in the MNA score resulted in missing data for 45 of the subjects The mean MNA score for both men (22.3 (SD 3.6), range 14-29) and women (23.0 (SD 3.3), range 10-29) fell in the 'at risk of malnutrition' category (i.e. 17-23.9). Five per cent of subjects were classified as being malnourished (i.e. MNA score $<17)$. Half the sample $(50.4 \%)$ were in the 'at risk' classification of nutritional status, while $44.4 \%$ were considered to be well nourished (i.e. MNA $\geq 24$ ).

\section{Development of mid-upper arm circumference (MUAC) reference values}

In order to develop appropriate cut-off reference values for assessment of nutritional status in South African elderly using MUAC measurements, mean MUAC values need to be assessed according to BMI categories of health risk ${ }^{14}$. Good associations were found between MUAC and BMI ( $r=0.86$ (women) and $r=0.89$ (men); $P<0.0001$ ). Regression analyses conducted between BMI and MUAC indicated the following:

$$
\begin{aligned}
\text { Men : } & \text { MUAC }=(0.65477 \times \mathrm{BMI})+11.74542 ; \\
\text { Women : } & \text { MUAC }=(0.68493 \times \mathrm{BMI})+11.27586 .
\end{aligned}
$$

Using these equations, new MUAC reference values are suggested for use in older black South Africans (Table 1) to classify subjects according to health-associated BMI categories. For both men and women, an MUAC value of $<24.0 \mathrm{~cm}$ corresponds to a BMI value indicative of underweight $\left(<18.5 \mathrm{~kg} \mathrm{~m}^{-2}\right)$.

\section{Development/validation of a new nutrition screening tool}

Step 1: Correspondence analysis

This allowed the identification, topic by topic, of the individual items included in the original questionnaire which best corresponded to a particular concept, by providing a low-dimensional graphical representation of the rows and columns of a cross-tabulation or contingency table. Correspondence analyses identify which questions within a general grouping have been answered in a similar way, i.e. according to 'Yes', 'No' and 'Don't know' responses in the case of categorical questions. For example, the 'motor disability' score asked subjects whether or not they had difficulty in performing six tasks. A decision was made to include this concept in the new screening tool because it was positively and significantly associated with MNA score, as well as with IADL score. The correspondence analyses found that only two of the six items (i.e. 'walking up 10 stairs' and doing 'heavy housework/yardwork') corresponded with a 'yes' response, while the other items all corresponded with a 'no' response. These two items were kept in the new tool, as being representative of the concept of 'motor disability'.

The MNA tool comprises four separate sections. In order to identify which concepts the various MNA sections include, and to identify which parts of the MNA the new

Table 1 Mean mid-upper arm circumference (MUAC) according to body mass index (BMI) category, calculated using regression

\begin{tabular}{|c|c|c|c|c|}
\hline & \multicolumn{4}{|c|}{ Corresponding BMI category } \\
\hline & $\begin{array}{l}<17 \mathrm{~kg} \mathrm{~m}^{-2} \\
\text { (moderately } \\
\text { underweight) }\end{array}$ & $\begin{array}{l}<18.5 \mathrm{~kg} \mathrm{~m}^{-2} \\
\text { (underweight) }\end{array}$ & $\begin{array}{l}\geq 25 \mathrm{~kg} \mathrm{~m}^{-2} \\
\text { (overweight) }\end{array}$ & $\begin{array}{l}\geq 30 \mathrm{~kg} \mathrm{~m}^{-2} \\
\text { (obese) }\end{array}$ \\
\hline \multicolumn{5}{|c|}{ MUAC (cm) } \\
\hline Men & 22.9 & $<23.9$ & $\geq 28.1$ & $\geq 31.4$ \\
\hline Women & 22.9 & $<23.9$ & $\geq 28.4$ & $\geq 31.8$ \\
\hline
\end{tabular}
analyses for older South Africans 
items would reflect, a brief summary of the MNA instrument is given below.

- MNA1 - (1) Anthropometric measurements (mid-arm circumference, calf circumference, BMI); (2) history of recent weight loss.

- MNA2 - (1) Living conditions (institutionalised vs. community-living); (2) medication use; (3) recent psychological stress; (4) transfer from bed to chair; (5) cognitive assessment; (6) pressure sores.

- MNA3 - (1) Number of meals per day; (2) dietary intake: diary, legumes/eggs, meat/fish/poultry; (3) fruit/vegetables intake; (4) recent loss of appetite; (5) fluid intake; (6) dependency in eating.

- MNA4 - (1) Self-perceived nutritional status; (2) selfperceived health status, compared with peers of the same age.

Table 2 summarises the results of the correspondence analyses, and indicates which of the MNA items (using the above reference numbering) were found to be appropriate for use in the study population.

\section{Step 2: Identification of key questions}

This allowed identification of key questions relating to each of the concepts. In cases where more than one key question was identified per concept, the principal researcher (K.C.), who is a state-registered dietitian with many years of research experience in geriatric nutrition in Africa, in her expert opinion decided which of the items (if any) should be omitted. Nine separate topics (comprising 16 individual items) were identified as being key questions as a result of, first, the correspondence analyses (i.e. as an objective measure) and second, through the input of the expert opinion (careful scrutiny of the descriptive associations with the MNA tool was made). Items identified in the correspondence analyses as being possibly valid indicators of the various concepts of interest, but that were later discarded during the expert opinion process, included the following:

- Cognitive function (months in reverse order);

- Medication prescribed for chronic conditions (hypertension and diabetes);

- Food habits - most people perceived their body size to be 'just right', ate their food 'lightly salted' or 'never' added extra salt to food, and did 'not' follow a special diet, therefore these items were not considered to be useful determinants of nutritional risk;

- Fluid intake per day (see Step 4 below);

- Food security - only one of the three identified items was included because they were all similar, in terms of correspondence, to the construct of inadequate access to food.

In order to simplify the new tool in terms of anthropometric measurements, only MUAC was included in the questionnaire, using a single cut-off value of $<24 \mathrm{~cm}$ as indicative of underweight.

\section{Step 3: Internal consistency/internal-comparison reliability}

This was estimated by determining the inter-correlation among the scores of the items on a multiple-item index. Internal consistency of the individual items, in relation to overall total score of the draft screening tool, is shown in Table 3. In the total sample, all selected items were positively and significantly associated with total score, except for 'uses, or in need of, spectacles/contact lenses'. This item was subsequently omitted from the screening tool. In men, six of the proposed items were not significantly associated with total score; however, this is probably due to the small sample size $(n=33)$. In women, only the repeated memory phrase item failed to show significance with total score, but the item was kept in the tool due its strong association in men. After this process, the nine concepts comprised a total of 15 individual items, including the measurement of MUAC.

\section{Step 4: Correlational analyses with objective measures}

Complete data on each item included in the new screening tool were available for 33 men and 178 women $(n=211$ subjects). Possible scores ranged from 0 to 23 on the new tool, compared with 0 to 24 on the MNA tool. For men, the mean new score was 15.3 (SD 4.07) (range 4-22; median 16.0). For women, mean score was 14.1 (SD 3.4) (range 6-22; median 14.0). Correlations between scores obtained using the new tool and the MNA instrument were positive and significant ( $r=0.737 ; P<0.0001 ; n=207$ ). A weaker correlation was found between the new tool scores and the MNA-SF scores ( $r=0.514 ; P<0.0001 ; n=184)$. The new scores were positively associated with both left $(r=0.180 ; P=0.0094 ; n=207)$ and right $(r=0.157$; $P=0.0235 ; n=209$ ) handgrip strength.

If 'use of, or need for, dentures' was added to the new score, correlation of the score with the MNA decreased, while if 'repeat months in reverse order' and 'no. of cups of fluid per day' were included in the new score, correlation of the new score with the MNA increased from 0.737 to 0.763. It was decided, however, to exclude these two items since one item on cognitive function (repeat memory phrase) was already included and the question relating to fluid intake may be difficult for older subjects to quantify.

Good agreement was found, in women, between the scores using the new tool and better performance on most of the physical function tests (static and dynamic balance, chair rise, get-up-and-go, $2.4 \mathrm{~m}$ walk (fast)) and with a higher (i.e. better) motor disability score (Table 4). In men, only the motor disability score was associated with the new score $(r=0.393)$; however, the correlation coefficient for functional reach was 0.249 (not significant). In both men and women, a good correlation with ADL score was found while the association between the new score and IADL 
Table 2 Summary of results of correspondence analyses

\begin{tabular}{|c|c|c|}
\hline Concept & $\begin{array}{l}\text { Individual item(s) identified by correspondence } \\
\text { analyses }\end{array}$ & Remark(s) \\
\hline Motor disability & $\begin{array}{l}\text { 1. Walking up } 10 \text { stairs } \\
\text { 2. Doing heavy housework/yardwork }\end{array}$ & $\begin{array}{l}\text { These two components could replace MNA2 } \\
\text { component (4) }\end{array}$ \\
\hline $\begin{array}{l}\text { Six-Item Cognitive Impairment } \\
\text { Test }(6 \mathrm{CIT})\end{array}$ & $\begin{array}{l}\text { 1. Memory phrase } \\
\text { 2. Months in reverse order } \\
\text { Present year and present } \\
\text { month excluded (too easy) }\end{array}$ & $\begin{array}{l}\text { Either item could replace the } 6 \mathrm{CIT} \text { test, i.e. } \\
\text { MNA2 component (5). Memory phrase } \\
\text { most difficult }\end{array}$ \\
\hline $\begin{array}{l}\text { Personal medical history and } \\
\text { self-perceived health status }\end{array}$ & $\begin{array}{l}\text { Use of health aids: } \\
\text { 1. Spectacles/contact lenses = 'Yes' } \\
\text { 2. Cane and dentures = 'No, but need to obtain' } \\
\text { 3. Wheelchair and hearing aid = 'No' (excluded - } \\
\text { too many 'No' responses) } \\
\text { Self-reported prevalence of chronic conditions: } \\
\text { 1. Hypertension and diabetes = 'Yes' } \\
\text { 2. Asthma, heart attack, high blood cholesterol, } \\
\text { stroke, other heart conditions = 'No' (excluded - }\end{array}$ & $\begin{array}{l}\text { No questions on disease prevalence included } \\
\text { in the MNA tool. The most relevant to } \\
\text { include would be hypertension-related; } \\
\text { however, there is no clear association } \\
\text { between nutritional status and risk for } \\
\text { hypertension (with the exception of a high } \\
\text { salt intake and obesity being possible risk } \\
\text { factors) }\end{array}$ \\
\hline
\end{tabular}

\section{Medication usage}

Food habits

Dietary intake and eating habits (excluding the 24-hour recall questionnaire)

Recent weight change and diet-related problems

Household food security and hunger
'Yes' correspondence analyses for the following items: "

Fruit/veg on most days'; '1 + servings

of dairy most days'; ' $2+$ beans/eggs servings per week'; 'Meat/fish/chicken most days'

'Eat less than 2 meals per day; alcohol; swallowing problems; loss/gain weight; able to cook, shop, feed self' = 'No' (excluded - mostly 'No' responses) 'Yes' correspondence analyses for the following items:

'Psychological stress in past 3 months';

'Acute illness in past 3 months'; 'No. of cups of fluid per day' (this item could be included)

Of a list of 14 items, only one corresponded to an 'Always' response - 'My food runs out before I get money to buy more'. There was a strong correspondence between this item and 'I still have food in the house the day before someone gets paid or gets their grant' (which loads strongly on 'Never' response). The item 'I have enough money for food' also corresponded to a 'Never' response
The item included in the MNA score, 'I take 3 or more prescribed or over-the-counter medications every day', was also included in our questionnaire, in addition to the questions on disease-specific medications. Suggested that this item is included in the new tool, as it is broad and covers all medications

These items were not included in the MNA tool. Too little variation in subjects' responses for the items to be useful in a new tool. No meaningful conclusions could be obtained from any of these items (exclude all)

The same items used in the MNA score were included here, in addition to 'Yes/No' items on habitual dietary intake included in the DETERMINE questionnaire. All items are useful

In the item that asked about nutritional problems, most subjects responded 'None'. Likewise, most subjects responded 'No loss of appetite'. These two items are included in the MNA tool (omit from new tool). Many of the other items in this concept are included in the DETERMINE tool, but we did not find good correspondence in our sample, which probably explains the low specificity and PPV of the DETERMINE tool in our study population $^{2}$. Items on psychological stress, acute illness, fluid intake included in MNA

It is suggested that any of these three items would adequately characterise household food insecurity (lack of access to food). The MNA tool does not include an item on affordability of food. This is important in the context of poor communities who do not have adequate financial provision for old age 
Table 2. Continued

\begin{tabular}{|c|c|c|}
\hline Concept & $\begin{array}{l}\text { Individual item(s) identified by correspondence } \\
\text { analyses }\end{array}$ & Remark(s) \\
\hline Social activities & $\begin{array}{l}\text { This concept includes participation in various social } \\
\text { activities, ADL, IADL smoking habits. 'Yes' = TV, } \\
\text { listening to radio, visiting (non-discriminatory } \\
\text { items). 'No' = newspaper reading, hobbies, } \\
\text { and maybe church attendance }\end{array}$ & $\begin{array}{l}\text { This concept not included in the MNA tool. } \\
\text { Participation may reflect not an inability to } \\
\text { perform the activities, but rather a lack of } \\
\text { resources needed to perform that activity } \\
\text { (e.g. owning a TV or radio, etc., or having } \\
\text { transport to get to church). For that reason, } \\
\text { this concept was not included in the new tool }\end{array}$ \\
\hline $\begin{array}{l}\text { Activities of daily living } \\
\text { (ADL) and instrumental } \\
\text { activities of daily living } \\
\text { (IADL) }\end{array}$ & $\begin{array}{l}\text { Of the } 14 \text { items, nine corresponded to 'Independent } \\
\text { without help', while three items corresponded } \\
\text { to 'Able to but need help' and two items } \\
\text { (shopping and housework) tend towards } \\
\text { 'Unable to perform' }\end{array}$ & $\begin{array}{l}\text { Ability to perform housework is already } \\
\text { included in the motor disability concept. } \\
\text { Two ADL items, transfer from a bed to a chair } \\
\text { and dependency in eating, are included in } \\
\text { the MNA3 and MNA2 indices, respectively }\end{array}$ \\
\hline
\end{tabular}

MNA - Mini Nutritional Assessment; PPV - positive predictive value.

score was significant only in women. Cognitive function score was inversely associated with new score, which means that subjects with a higher nutritional score were less cognitively impaired than those with a lower score. The new score was not associated with anthropometric measurements, with the exception of a positive relationship with arm muscle area in women.

Step 5: Determination of reference cut-off values for categories of nutritional risk using regression analyses The following regression models can be used to predict cut-off score values, according to the three MNA categories of risk:

$$
\begin{aligned}
\text { Men : } & (0.96102 \times \text { MNA score })-6.95833 ; \\
\text { Women : } & (0.74562 \times \text { MNA score })-3.35181 ; \\
\text { Total : } & (0.77286 \times \text { MNA score })-3.78696 .
\end{aligned}
$$

An MNA score of 17 (i.e. 'malnourished') corresponds to a score of 9.4 for both men and women, and an MNA score of 24 (i.e. 'well nourished') corresponds to a score of 16.1 for men and 14.5 for women on the new screening tool. Differences in ADL, IADL, physical function tests, dietary intake of energy, protein, vitamins $\mathrm{C}$ and $\mathrm{A}$, and anthropometric measurements between subjects in these categories of risk are shown in Table 5.

Well nourished subjects had better scores on both the ADL and IADL than the other two groups, indicating a greater independence in performing these tasks. Performance on the physical function tests tended to increase across the three categories, with subjects in the malnourished category having significantly poorer performance in the get-up-and-go and chair rise tests (both measures of lower-body strength) (Fig. 1), as well as having poorer balance, slower walking speed, lower grip strength and a lower score on the IADL index (Fig. 2).

The new tool categories were also able to characterise subjects according to cognitive function. Mean score on the

\begin{tabular}{|c|c|c|c|}
\hline Individual item & Men $(n=33)$ & Women $(n=178)$ & $\begin{array}{l}\text { Total sample } \\
\quad(n=211)\end{array}$ \\
\hline Ability to walk up 10 steps & $0.347^{*}$ & $0.464^{\star \star \star}$ & $0.478^{\star \star \star}$ \\
\hline Ability to do heavy housework & 0.194 & $0.434^{* * *}$ & $0.421^{\star \star \star}$ \\
\hline Repeated memory phrase & $0.433^{\star}$ & 0.113 & $0.150^{\star}$ \\
\hline Self-perceived health status, compared with peers & $0.495^{\star \star}$ & $0.488^{\star \star *}$ & $0.496^{\star \star \star}$ \\
\hline Use, or need for, cane/crutch/walking frame & $0.356^{\star}$ & $0.366^{\star \star \star}$ & $0.391^{\star * *}$ \\
\hline Use, or need for, spectacles/contact lenses & -0.222 & -0.012 & -0.036 \\
\hline Less than 2 meals per day & 0.245 & $0.280^{\star *}$ & $0.285^{\star \star \star}$ \\
\hline Fruit/vegetable intake & 0.233 & $0.301^{\star * *}$ & $0.268^{\star * \star}$ \\
\hline Dairy product intake & $0.497^{\star *}$ & $0.285^{\star * *}$ & $0.287^{* * *}$ \\
\hline Eggs/beans intake & $0.475^{\star}$ & $0.202^{*}$ & $0.252^{\star *}$ \\
\hline Meat/fish/poultry intake & $0.587^{\star \star}$ & $0.239^{* *}$ & $0.286^{\star * *}$ \\
\hline Food security & $0.416^{\star}$ & $0.419^{\star \star}$ & $0.418^{\star \star \star}$ \\
\hline Recent psychological stress & $0.518^{\star \star}$ & $0.490^{\star \star}$ & $0.497^{\star \star \star}$ \\
\hline Recent acute illness & $0.694^{* * *}$ & $0.346^{* * *}$ & $0.408^{\star * \star}$ \\
\hline Use of 3 or more medications & 0.084 & $0.296^{\star \star *}$ & $0.280^{\star * \star}$ \\
\hline Arm circumference cut-off values & 0.209 & $0.219^{* *}$ & $0.194^{\star *}$ \\
\hline
\end{tabular}

Table 3 Internal consistency between individual items and total score in the draft new screening tool: Spearman correlation coefficients

Significance of Spearman correlation coefficient: ${ }^{*}, P<0.05 ;{ }^{* \star}, P<0.005 ;{ }^{\star \star \star}, P<0.0001$. 
Table 4 Association between new tool score and physical function test results, anthropometry, level of independence and nutritional status: Spearman correlation coefficients

\begin{tabular}{|c|c|c|c|}
\hline Physical test & Men $(n=33)$ & Women $(n=178)$ & $\begin{array}{c}\text { Total sample } \\
\quad(n=211)\end{array}$ \\
\hline MNA score & $0.818^{\star \star \star}$ & $0.733^{* * *}$ & $0.737^{* * *}$ \\
\hline Static balance (parallel feet) $(s) \dagger$ & -0.056 & $0.254^{\star \star}$ & $0.213^{\star \star}$ \\
\hline Dynamic balance (score for no. of steps taken)† & 0.261 & $0.261^{\star *}$ & $0.258^{\star *}$ \\
\hline Functional reach $(\mathrm{cm}) \dagger$ & 0.249 & 0.119 & $0.174^{*}$ \\
\hline Sit-to-stand (s)‡ & -0.035 & $-0.254^{\star \star}$ & $-0.229^{\star \star}$ \\
\hline Get-up-and-go (s)‡ & -0.074 & $-0.244^{\star \star}$ & $-0.203^{\star *}$ \\
\hline $2.4 \mathrm{~m}$ walk $(\mathrm{s}) \ddagger$ & -0.031 & $0.186^{*}$ & $0.149^{\star}$ \\
\hline $2.4 \mathrm{~m}$ walk, as fast as possible (s) $\ddagger$ & 0.069 & $-0.281^{\star \star}$ & $-0.247^{\star \star}$ \\
\hline Motor disability score & $0.393^{*}$ & $0.530^{\star \star \star}$ & $0.557^{\star \star \star}$ \\
\hline ADL score (Barthel) & $0.386^{*}$ & $0.497^{\star * *}$ & $0.472^{\star \star \star}$ \\
\hline IADL score & 0.227 & $0.242^{\star *}$ & $0.232^{\star \star}$ \\
\hline Handgrip strength (left) (kg) & 0.152 & $0.149^{*}$ & $0.180^{*}$ \\
\hline Handgrip strength (right) (kg) & 0.122 & 0.087 & $0.157^{*}$ \\
\hline Mid-upper arm circumference (cm) & 0.150 & $0.173^{\star}$ & 0.113 \\
\hline Body mass index $\left(\mathrm{kg} \mathrm{m}^{-2}\right)$ & 0.056 & 0.125 & 0.048 \\
\hline$\%$ Lean body mass & -0.016 & -0.029 & 0.056 \\
\hline Corrected arm muscle area $\left(\mathrm{cm}^{2}\right)$ & -0.122 & $0.157^{*}$ & 0.073 \\
\hline Triceps skinfold thickness $(\mathrm{cm})$ & 0.218 & 0.104 & 0.084 \\
\hline Calf circumference $(\mathrm{cm})$ & 0.068 & 0.065 & 0.031 \\
\hline Cognitive function score (6CIT) & $-0.330 \dagger \dagger$ & $-0.217^{\star \star}$ & $-0.206^{\star \star}$ \\
\hline
\end{tabular}

MNA - Mini Nutritional Assessment; ADL - activities of daily living; IADL - instrumental activities of daily living; 6CIT - Six-Item Cognitive Impairment Test.

Significance of Spearman correlation coefficient: *, $P<0.05 ;{ }^{* *}, P<0.005 ;{ }^{* * *}, P<0.0001 ; \dagger \dagger, P=0.0582$.

† Higher score indicates better performance.

$\ddagger$ Longer time indicates poorer physical function.

6CIT index increased across the categories of nutritional risk $(P<0.05)$. Well nourished subjects had a mean score $(8.65$ (SD 7.47)) which fell in the normal cognitive function range compared with subjects classified as either malnourished (14.12 (SD 9.12)) or at nutritional risk (11.1 (SD 4.42)), whose mean 6CIT score indicated cognitive impairment.
Dietary intakes of energy, protein and vitamin C tended to be higher in the better nourished subjects, and vitamin A intake was almost three times lower $(P<0.05)$ in malnourished subjects compared with their peers. Differences between the remainder of the reported nutrient intakes were not investigated.

Table 5 Physical function test results, anthropometric measurements, activities of daily living (ADL), instrumental activities of daily living (IADL) and nutrient intake, according to scoring categories of new tool: mean value (standard deviation)

\begin{tabular}{|c|c|c|c|}
\hline Measurement & $\begin{array}{l}\text { Malnourished } \\
\text { Score }<9.5\end{array}$ & $\begin{array}{l}\text { At risk of malnutrition } \\
\text { Score }=9.5-14.5 \text { (men) } \\
\text { and } 9.5-16 \text { (women) }\end{array}$ & $\begin{array}{c}\text { Well nourished } \\
\text { Score }>14.5 \text { (men) } \\
\text { and }>16 \text { (women) }\end{array}$ \\
\hline$n$ & 17 & 99 & 95 \\
\hline MNA score & $17.5(3.3)$ & $22.3(2.4)$ & $25.6(2.2)^{\star \star \star}$ \\
\hline Body mass index $\left(\mathrm{kg} \mathrm{m}^{-2}\right)$ & $26.1(7.6)$ & $32.3(9.2)$ & $32.3(7.5)$ \\
\hline Mid-upper arm circumference $(\mathrm{cm})$ & $30.3(6.4)$ & $33.1(6.4)$ & $34.1(6.1)$ \\
\hline$\%$ Lean body mass & $60.6(10.7)$ & $51.8(8.9)$ & $52.4(8.5)^{\star}$ \\
\hline Arm muscle area $\left(\mathrm{cm}^{2}\right)$ & $36.3(19.5)$ & $38.3(19.9)$ & $44.1(20.2)$ \\
\hline Grip strength (left) (kg) & $15.7(4.9)$ & $16.5(6.4)$ & $17.8(6.1)$ \\
\hline ADL score (Barthel) & $12.1(3.1)$ & $13.8(1.4)$ & $14.8(1.4)^{* \star *}$ \\
\hline IADL score & $10.7(5.0)$ & $11.7(4.7)$ & $13.9(3.6)^{\star \star}$ \\
\hline Static balance $(\mathrm{s}) \dagger$ & $11.1(13.0)$ & $15.9(13.4)$ & $20.3(12.8)^{*}$ \\
\hline Get-up-and-go (s)‡ & $87.3(58.6)$ & $85.4(57.7)$ & $50.5(42.9)^{\star \star}$ \\
\hline Sit-to-stand (s) $\ddagger$ & $127.4(85.3)$ & $141.7(173.3)$ & $79.1(126.4)^{*}$ \\
\hline Walking 2.4 m (fast) (s)‡ & $23.0(21.6)$ & $22.6(18.0)$ & $11.3(8.6)^{\star \star \star}$ \\
\hline Motor disability score† & $1.35(0.43)$ & $1.93(0.24)$ & $1.78(0.22)^{\star \star \star}$ \\
\hline Cognitive function score (6CIT) & $14.12(9.12)$ & $11.14(7.42)$ & $8.65(7.47)^{\star}$ \\
\hline Energy intake $\left(\mathrm{kJ} \mathrm{day}^{-1}\right)$ & $5174(2085)$ & $5810(2272)$ & 5929 (1904) \\
\hline Protein intake $\left(\mathrm{g} \mathrm{day}^{-1}\right)$ & $43.4(18.7)$ & $50.4(25.3)$ & $53.7(24.0)$ \\
\hline Vitamin $C$ intake $\left(\right.$ mg day $\left.^{-1}\right)$ & $19.1(15.7)$ & $40.9(58.6)$ & $45.6(69.9)$ \\
\hline Vitamin A intake $\left(\mu \text { g day }^{-1}\right)^{\prime}$ & $222(460)$ & $682(1324)$ & $620(1115)^{*}$ \\
\hline
\end{tabular}

MNA -Mini Nutritional Assessment; 6CIT - Six-Item Cognitive Impairment Test.

Significant difference between categories (analysis of variance): ${ }^{*}, P<0.05 ;{ }^{* *}, P<0.005 ;{ }^{* * *}, P<0.0001$.

$\dagger$ Higher score/time indicates better performance.

$\ddagger$ Longer time indicates poorer physical function. 


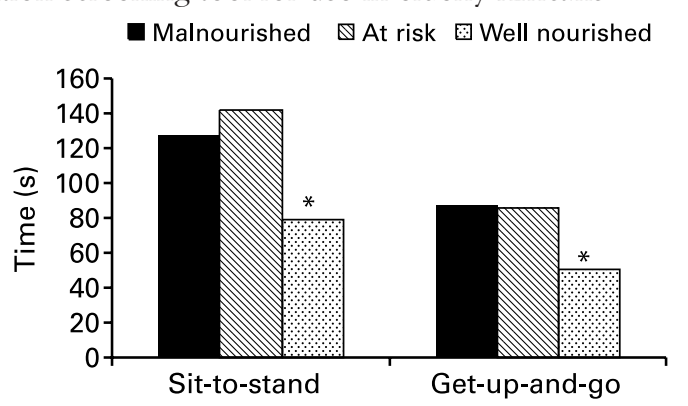

Fig. 1 Measures of lower-body strength according to nutritional risk category as assessed using the new screening tool, where a shorter time indicates better physical function. Significant difference between categories (analysis of variance): ${ }^{*}, P<0.05$

\section{Step 6: Determination of sensitivity and specificity of the new screening tool}

A comparison between the number of subjects who were classified in the three categories of risk, according to the new screening tool and the MNA and DETERMINE instruments, is shown in Fig. 3. Sensitivity, specificity, and positive and negative predictive values of the new screening tool was assessed in the following ways:

- Nutritional risk (malnourished and at risk, combined) versus well nourished

- Sensitivity: proportion of 'malnourished' or 'at risk' individuals classified by the new tool who were correctly identified as such by the MNA tool (82.1\%; $n=87 / 106$ ).

- Specificity: proportion of 'well nourished' individuals classified by the new tool who were correctly identified as such by the MNA tool (72.3\%; $n=73 / 101$ ).

- Positive predictive value: proportion of subjects classified by new tool as being either 'malnourished' or 'at risk' who were correctly identified (75.7\%; $n=87 / 115$ )

- Negative predictive value: proportion of subjects classified by new tool as being 'well nourished' who were correctly identified (79.3\%; $n=73 / 92)$.

- Malnourished versus at risk/well nourished combined

- Sensitivity: proportion of 'malnourished' individuals classified by the new tool who were correctly identified as such by the MNA tool $(87.5 \% ; n=7 / 8)$.

- Specificity: proportion of 'at risk' or 'well nourished' individuals classified by the new tool who were correctly identified as such by the MNA tool (95.0\%; $n=189 / 199$ ).

- Positive predictive value: proportion of subjects classified by new tool as being 'malnourished' who were correctly identified (41.2\%; $n=7 / 17)$.

- Negative predictive value: proportion of subjects classified by new tool as being 'at risk' or 'well nourished' who were correctly identified (99.5\%; $n=189 / 190)$.

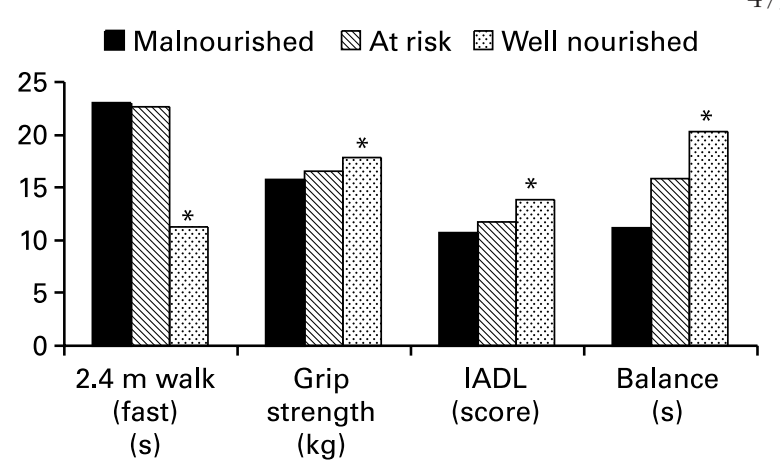

Fig. 2 Walking capacity, grip strength, level of independence (instrumental activities of daily living, IADL) and balance according to nutritional risk category as assessed using the new screening tool, where a longer time for walking capacity indicates poorer physical function and a higher score/time for the remaining activities indicates better physical performance. Significant difference between categories (analysis of variance): *,$P<0.05$

Regarding sensitivity of the new tool compared to the MNA-SF, 14 of the 15 subjects (93.3\%) classified as malnourished on the new tool were classified as undernourished by the MNA-SF (score <11). However, only 41 of the 90 subjects (45.6\%) classified at nutritional risk by the new tool had an MNA-SF score below 11. Specificity was 82.3\%; 65 of the 79 subjects classified as well nourished on the new tool had an MNA-SF score of normal.

\section{Discussion}

Given the lack of adequate geriatric care at primary health facilities in South Africa ${ }^{15}$, the paucity of equipment and the poor morale of health professionals working in the public healthcare system, an important requirement of the new tool is that it could be administered quickly, without the need for blood analyses, or complex measurements of body composition. The new tool was developed using a systematic approach, through which important key questions able to reflect various concepts were identified. The draft instrument was found to be associated with many objective indicators of nutritional status (i.e. reported dietary data, anthropometric indices, and cognitive and physical function measures) and the internal consistency of the tool was found to be high. Nine separate concepts, comprising a total of 14 questions, are included in the proposed nutrition screening tool, as well as measurement of MUAC (Appendix). Similarly to the MNA scoring system, for each of the items in the new tool a higher score indicates better nutritional status.

Four underlying needs to counter malnutrition in developing countries have been identified by the United Nations ${ }^{16}$. These include (1) adequate household food security, allowing a 'balanced' diet; (2) adequate caring capacity; (3) sufficient health services; and (4) a healthy environment. The rationale for including a measure of food security in the new screening tool relates to the high 
MNA $\mathbb{Q}$ DETERMINE New tool

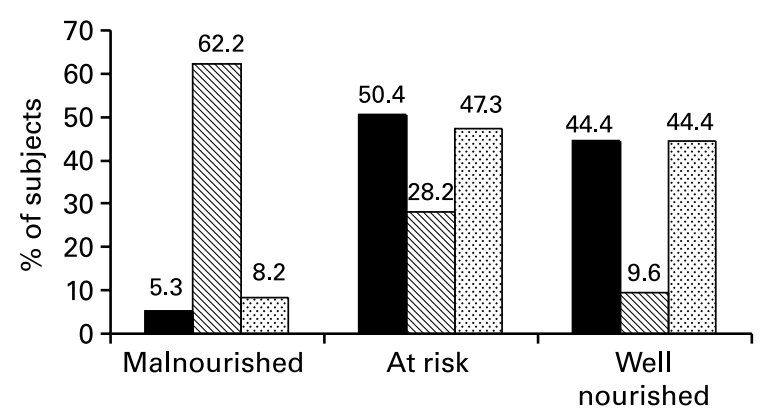

Fig. 3 Classification of subjects into nutritional risk category according to instrument: the Mini Nutritional Assessment (MNA), DETERMINE and the new tool

reported level of inadequate access to food in the present study (detailed elsewhere) ${ }^{17}$, as well as to published secondary data analyses from a large income and expenditure survey, conducted in 1995, in a nationally representative sample of 28704 South African households $^{18,19}$. In that study, $50 \%$ of elderly-headed households (i.e. headed by a person aged $60+$ years) ( $n=7194$ households), compared with $40.1 \%$ of younger-headed households ( $n=21510$ ), were identified to be in 'food poverty' (i.e. unable to afford a basic subsistence diet) ${ }^{20}$. Dramatic differences in food poverty were evident according to ethnicity and age of household head, with black elderly-headed households having the highest food poverty rates of all groups in the country (65.4\%), despite the existence of a non-contributory oldage social pension. Increasing household size increased the risk of food poverty in older households, which suggests that, contrary to 'living alone' being a risk factor for nutritional problems as is the case in Europe and the $\mathrm{USA}^{21-23}$, living with other family members appears to increase the risk of inadequate access to food in elderly subjects. The inclusion of a robust indicator of selfperceived adequacy of access to food was thus considered to be essential in the development of a nutrition screening tool intended for use in this population.

The choice of a single anthropometric measurement (i.e. MUAC) in the final screening tool also warrants further explanation. It has been suggested that conventional BMI reference values may not be appropriate for identifying poor nutritional status in elderly people, because of changes in body composition and kyphosis. The circumference of the mid-upper arm is an easy-to-perform measurement that requires only a tape measure, and may therefore be useful as a rapid and simple method to assess undernutrition. Collaborative studies conducted by the London School of Hygiene and Tropical Medicine (LSHTM) and HelpAge International have demonstrated that an MUAC value of below $24 \mathrm{~cm}$ is indicative of malnutrition in older Africans and have suggested four reference values, to indicate undernutrition of varying degrees ${ }^{24-26}$. Undernutrition, as measured by MUAC, in these studies was shown to be associated with functional ability (including handgrip strength), psychomotor speed and co-ordination, mobility and the ability to carry out activities of daily living independently - in both Malawi and Tanzania ${ }^{25,26}$. Regression modelling on data in the present study found almost identical MUAC reference values corresponding to the various BMI categories of nutritional risk, as the LSTHM/ HelpAge research group. However, because of the low number of subjects in the severe malnutrition group (i.e. BMI $<16 \mathrm{~kg} \mathrm{~m}^{-2}$ ), we recommend a simpler classification, using only three, rather than four, reference values to be used in older black South Africans: $<23 \mathrm{~cm}$ (moderate/ severe undernutrition); $23-23.9 \mathrm{~cm}$ (mild undernutrition); and $\geq 24 \mathrm{~cm}$ (well nourished). For the purposes of simplification and inclusion of this measurement in a nutrition screening tool, our data support the use of a single reference cut-off value $(<24 \mathrm{~cm})$ to assess risk of undernutrition. The high proportion of elderly women who had a BMI indicative of overweight or obesity identifies a need for a MUAC reference value for overnutrition.

The new tool appears to have good sensitivity and specificity in terms of being able to classify subjects who are malnourished/at risk of malnutrition. None of the eight subjects who were classified by the MNA as being malnourished fell into the well nourished category using the new tool (i.e. no false negatives). The fairly low positive predictive value $(41.2 \%)$ of the new tool in determining the greatest risk category (malnourished, compared with at risk/well nourished combined) means that 10 of the 17 subjects classified as being malnourished were false positives. All 10 of these misclassified subjects were in the 'at risk' category using the MNA scoring system. However, this is less important than having a tool with a low negative predictive value (i.e. false negatives), since the aim of a nutrition screening tool is to identify individuals at risk of malnutrition, for the purpose of early intervention and prevention of subsequent disability. Nutritional interventions will not necessarily harm those subjects who are not actually malnourished, unlike the prescription of potentially harmful drugs or other therapies in the case of a screening tool developed to identify other medical conditions. In the case of the new tool, the negative predictive value is extremely high.

An inherent methodological problem with the present study is that the new screening tool has been developed and 'validated' in the same population. In the current climate of a dearth of research funding in the field of nutrition and the elderly in developing countries (most available funding is allocated to childhood nutrition and the impact of nutritional interventions in people living with HIV/AIDS), we have attempted to make maximal use of the vast amount of information that was collected. Indeed, the shortened version of the MNA (MNA-SF) was originally developed and tested through secondary analyses from the same population in which the original 
MNA was developed and tested ${ }^{27}$. Undoubtedly, further validation of the new tool is required, in a new population of elderly Africans in which the MNA and objective measures of nutritional status are repeated.

\section{Conclusion}

A proposed new, simplified screening tool has been shown to have content-, construct- and criterion-related validity (at least against the MNA tool), and the individual items have been shown to have good internal consistency. The MUAC measurement may be used as a proxy for BMI in this population and reference cut-off values have been identified. The inclusion of a standardised set of short questions will allow comparison between elderly populations from different countries in Africa, and identify (within-country) sectors of the elderly population most in need of nutritional intervention.

\section{Acknowledgements}

Financial support for this study was provided by the Minimum Data Set (MDS) Project of the World Health Organization (WHO). Financial support for the MDS Project was provided under a grant from the Behavioral and Social Research Program of the US National Institute on Aging, within the US Department of Health and Human Services National Institutes of Health, through an Interagency Agreement with the WHO.

\section{References}

1 Vellas B, Garry PJ, Guigoz Y, eds. Mini Nutritional Assessment (MNA): Research and Practice in the Elderly. Nestle Nutrition Workshop Series, Clinical and Performance Programme, Vol. 1. Basel: Nestle Nutrition Services, 1999.

2 Charlton KE, Kolbe-Alexander TL, Nel JH. The MNA, but not the DETERMINE, screening tool is a valid indicator of nutritional status in elderly Africans. Journal of Nutrition, Health \& Aging 2005: in press.

3 Rubenstein LZ, Harker JO, Salva A, Guigoz Y, Vellas B. Screening for undernutrition in geriatric practice. Journals of Gerontology Series A: Biological Sciences and Medical Sciences 2001; 56: M366-72.

4 Faul AC, Hanekom AJ, Hanekom SM. Hunger and Food Security Assessment Scale. Silverton, OR: Perspective Training College, 1998.

5 White JV, Dwyer JT, Posner BM, Ham RJ, Lipsdhitz DA, Wellman NS. Nutrition screening initiative: development and implementation of the public awareness checklist and screening tools. Journal of the American Dietetic Association 1992; 92: 163-7.

6 Matthias RE, Lubben JE, Atchison KA, Schweitzen SO. Sexual activity and satisfaction among very old adults: results from a community-dwelling Medicare population survey. Gerontologist 1997; 37: 6-14.

7 Katz SC, Stroud MW. Functional assessment in geriatrics: a review of progress and directions. Journal of the American Geriatrics Society 1989; 37: 267-71.

8 Mahoney FI, Barthel DW. Functional evaluation: the Barthel Index. Maryland State Medical Journal 1965; 14: 61-5.
9 Lawton MP, Brody EM. Assessment of older people: self-maintaining and instrumental activities of daily living. Gerontologist 1969; 9: 179-86.

10 Rantanen T, Guralnick JM, Sakari-Rantala R, Leveille S, Simonsick EM, Ling S, et al. Disability, physical activity and muscle strength in older women: The Women's Health and Aging Study. Archives of Physical Medicine and Rehabilitation 1990; 80: 130-5.

11 Broderick K. Correlation between scores on two screening tools for dementia in Xhosa women. South African Journal of Occupational Therapy 2002; 32: 8-13.

12 Brooke P, Bullock R. Validation of a 6-item cognitive impairment test with a view to primary care usage. International Journal of Geriatric Psychiatry 1999; 14: 936-40.

13 Katzman MD, Brown T, Fuld F, Peck A, Scechter R, Scimmel H. Validation of a short orientation-memoryconcentration test of cognitive impairment. American Journal of Psychiatry 1983; 140: 734-9.

14 World Health Organization (WHO). Obesity: Preventing and Managing the Global Epidemic. Report on a Consultative Meeting. Geneva: WHO, 1997.

15 Louw S. Geriatric medicine in South Africa - the onus is on medical schools. South African Medical Journal 1997; 87: 1099-100.

16 United Nations Administrative Committee on Co-ordination/ Subcommittee on Nutrition (ACC/SCN). Update on the Nutrition Situation 1996. Geneva: ACC/SCN, 1996.

17 Charlton KE, Kolbe T, Nel H. Nutritional status of older black South Africans: towards the development of a nutrition screening tool for use in this population. Report submitted to the Minimum Data Set Project of the World Health Organization. Observatory: University of Cape Town, 2003 [unpublished].

18 Rose D, Charlton KE. Prevalence of household food poverty in South Africa: results from a large nationally representative survey. Public Health Nutrition 2002; 5(3): 383-9.

19 Rose D, Charlton KE. Quantitative indicators from a food expenditure survey can be used to target the food insecure in South Africa. Journal of Nutrition 2002; 132: 3235-42.

20 Charlton KE, Rose D. Nutrition among older adults in Africa: the situation at the beginning of the millennium. Journal of Nutrition 2001; 131: 2424S-8S.

21 Murphy SP, Davis MA, Neuhaus JM, Lenin D. Actors influencing the dietary adequacy and energy intake of older Americans. Journal of Nutrition Education 1990; 22: 284-91.

22 Walker D, Beauchene RE. The relationship of loneliness, social isolation, and physical health to dietary adequacy of independently living elderly. Journal of the American Dietetic Association 1991; 91: 300-4.

23 Charlton KE. Elderly men living alone: are they at high nutritional risk? Journal of Nutrition, Health \& Aging 1999; 3: $42-7$.

24 Ismail S, Manandhar M. Better Nutrition for Older People: Assessment and Action. London: HelpAge International and London School of Hygiene and Tropical Medicine, 1999.

25 Chilima DM, Ismail SJ. Nutrition and handgrip strength of older adults in rural Malawi. Public Health Nutrition 2000; 4 : $11-7$.

26 Pieterse S. Nutritional vulnerability of older refugees. $\mathrm{PhD}$ thesis, London School of Hygiene and Tropical Medicine, UK, 1999.

27 Rubenstein LZ, Harker J, Guigoz Y, Vellas B. Comprehensive geriatric assessment (CGA) and the MNA: an overview of CGA, nutritional assessment, and development of a shortened version of the MNA. In: Vellas B, Garry PJ, Guigoz Y, eds. Mini Nutritional Assessment (MNA): Research and Practice in the Elderly. Nestle Nutrition Workshop Series, Clinical and Performance Programme, Vol. 1. Basel: Nestle Nutrition Services, 1999. 
Appendix:

Nutrition screening tool for use in elderly South Africans

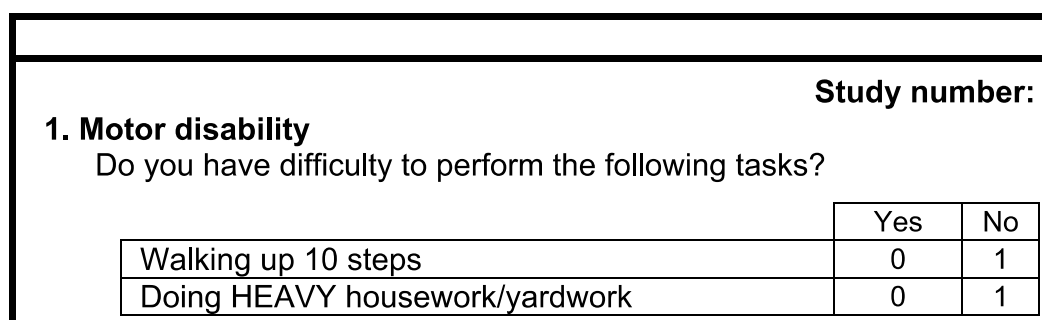

\section{Cognitive function (memory)}

Please repeat the following phrase (address) after me:

Pumla/ Zibi/ Z69/ Jama Road/Khayelitsha

(Note: This address phrase can be changed to be appropriate to the subjects' area of residence)

\section{Self-perceived health status}

Would you say that your health is better, about the same, or not as good as that of most people your age?

\begin{tabular}{|l|c|}
\cline { 2 - 2 } \multicolumn{1}{c|}{} & Score \\
\hline Better & 2 \\
\hline About the same & 1 \\
\hline Not as good & 0 \\
\hline
\end{tabular}

4. Use of and need for health aids

Do you use, or need to obtain the following:

\begin{tabular}{|l|c|c|c|}
\cline { 2 - 4 } \multicolumn{1}{c|}{} & $\begin{array}{c}\text { Yes / refuses } \\
\text { to say }\end{array}$ & $\begin{array}{c}\text { No, but I need to } \\
\text { obtain this aid }\end{array}$ & $\begin{array}{c}\text { No, I don't } \\
\text { need this aid }\end{array}$ \\
\hline $\begin{array}{l}\text { Cane / crutch / } \\
\text { walking frame }\end{array}$ & 0 & 0.5 & 1 \\
\hline
\end{tabular}

5. Cognitive function (repeat memory phrase)

Please repeat the address I told you previously:

Pumla/ Zibi/ Z69/ Jama Road/ Khayelitsha

No errors in recalling the address

1 or more errors in recalling phrase

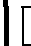

+

(1)

6. Number of meals per day

I eat less than 2 meals per day

\begin{tabular}{|l|c|}
\cline { 2 - 2 } \multicolumn{1}{c|}{} & Score \\
\hline Yes/don't know & 0 \\
\hline No & 2 \\
\hline
\end{tabular}




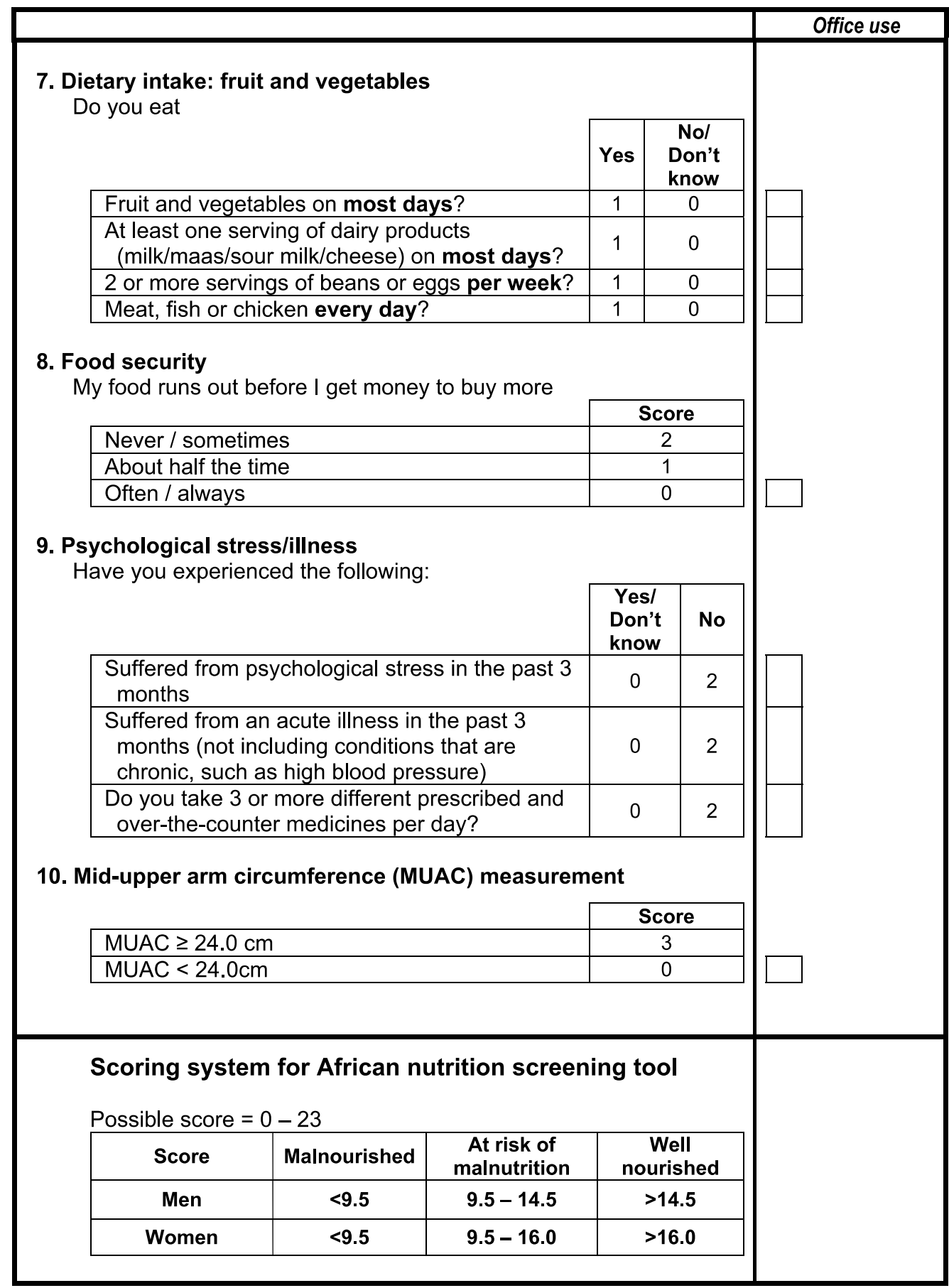

